\title{
Earth electricity: a review of mechanisms which cause telluric currents in the lithosphere
}

\author{
Daniel S. Helman
}

California State University Long Beach, Department of Geological Sciences, Long Beach, CA, United States

\author{
Article history \\ Received August 9, 2012; accepted June 27, 2013. \\ Subject classification: \\ Magnetosphere, Magnetic storms, Mineral physics and properties of rocks, Exploration geophysics, Magnetic and electrical \\ methods, Geology, Space and planetary sciences, Solar-terrestrial interaction.
}

\begin{abstract}
Telluric currents are natural electrical phenomena in the Earth or its bodies of water. The strongest electric currents are related to lightning phenomena or space weather. Earth electricity can cause damage to structures, and may be useful for earthquake forecasting and other applications. Thirty-two distinct mechanisms that cause Earth electricity are described, and a broad selection of current research is highlighted.
\end{abstract}

\section{Introduction}

Several phenomena that can generate telluric currents have been described in scientific specializations whose members may not communicate with each other regularly. The study of this topic is both intriguing and challenging: Electrical signals do not carry much of a marker to indicate how they are generated, beyond magnitude, frequency, and polarization. Attenuation and new phenomena caused by transmission complicate signal characteristics. A wide range of possible applications for telluric data exists in different fields (seismology, hydrology, mineral prospecting, geothermal prospecting, planetary science, etc.) For example, seismic electric signals may occur in a period leading to increased seismic risk, and understanding the causes of purported seismic electric signals is critical to characterizing any extant mechanism related to electricity and earthquake phenomena [Varotsos et al. 2011]. As another example, dissolved ions in groundwater increase rock conductivity, and the motion of the groundwater itself creates an electrical signal [Corwin and Hoover 1979]. This text is a brief selection of research in the subject, meant to be a resource for further study. Along with artificial signals, Earth electrical phenomena are summarized in Table 1 , and Table 2 lists telluric currents by frequency, magnitude and signal duration. Thirty-two causes of Earth electricity are described in the text that follows. Tel- luric currents were originally defined as natural electric currents passing through the Earth's soil or rock layers or bodies of water, as opposed to its atmosphere. Artificial currents were not included. For the purposes of this paper, any electric current in a planet or on it may be classed as a telluric current.

\section{Space phenomena}

\subsection{Geomagnetically-induced currents, GIC}

The ionosphere is composed of charged particles and located 85 to $600 \mathrm{~km}$ above the Earth's surface. Electrical phenomena are caused as the solar wind or space weather impact the ionosphere. The solar wind and space weather create ionospheric electromagnetic phenomena in the radio spectrum, and these disrupt communication. Eddies in the ionosphere also occur, and these create electric current in situ, from the motion of ions. This electric current affects the geomagnetic field, and the resulting geomagnetic anomalies induce telluric currents in the ground [Boteler et al. 1998]. This is GIC. Geomagnetically-induced currents cause corrosion in pipes and pipelines, and are a problem at high latitudes, where the Earth's magnetic flux lines point towards (or away from) the surface of the Earth.

Ore, or other rock bodies, or human-made structures, such as pipes and cables, respond to electrical changes in the ionosphere, so that a telluric current is induced in the ground. Osella et al. [1998], Everett and Martinec [2003], Constable and Constable [2004], Pulkkinen et al. [2007], and others have studied this phenomenon. Cycles are related to space weather, and are dominated by the influence of the Sun's eleven-year sunspot cycle, whose period predicts emissions of gas from the solar surface. Diurnal variations within this larger cycle have been recorded [Diodati et al. 2001]. 


\begin{tabular}{lccc}
\hline Name & Cause & Cycle & Mechanism \\
\hline Space Phenomena & Solar & $11 / 24 \mathrm{hr}$ & Electromagnetic Induction \\
GIC & $\begin{array}{c}\text { Cosmic } \\
\text { Cosmic Events } \\
\text { (Magnetotail) }\end{array}$ & $\begin{array}{c}\text { Not Known } \\
\text { Not Known } \\
28 \mathrm{~d}\end{array}$ & $\begin{array}{l}\text { Charge Transmission } \\
\text { Charge Transmission }\end{array}$
\end{tabular}

Atmospheric Phenomena

TID

Lightning Strikes

Lightning Strikes Induction

Whistler Induction

Whistler Plasma

Volcanic Lightning Strikes

Storm Charging

Oceanic Phenomena

Electrochemical Effects

Ocean Transport Induction

Oceanic Charging

Metabolic Electrochemistry

Surface Phenomena

Artificial Signals

Metabolic Electrochemistry

Exo-Electron Emission

Groundwater Phenomena

Electrochemical Effects

Electrokinetic Effects

Seismic Dynamo Induction

Radioactive Ionization

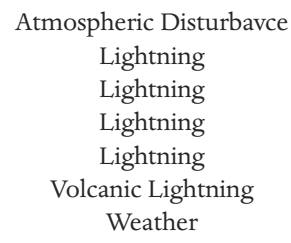

Atmospheric Disturbavce

Lightning

Lightning

Lightning

Lightning

Volcanic Lightning

Weather

\section{Not Known \\ Seasonal \\ Seasonal \\ Seasonal \\ Seasonal \\ Not Known \\ Seasonal}
Electromagnetic Induction Charge Transmission Electromagnetic Induction Electromagnetic Induction Charge Transmission Charge Transmission Electrostatic Induction

\section{Other Terrestrial Phenomena}

\author{
Volcanic EM Signals \\ Seismic EM Signals \\ Seismic Electric Signals \\ Fractoemission \\ Defect Charging \\ Piezoelectric Effects \\ Thermoelectric Effects \\ Pyroelectric Effects \\ Magma Electrochemistry \\ Radioactive Emission
}

$\begin{array}{cc}\text { Ocean Currents } & \text { Seasonal } \\ \text { Ocean Currents } & \text { Seasonal } \\ \text { Ocean Electric Currents } & \text { Seasonal } \\ \text { Microbes and Algae } & \text { Not Known }\end{array}$

Charge Transmission Electromagnetic Induction Electromagnetic Induction Charge Transmission

Deep Terrestrial Phenomena

Geomagnetic Jerk

Fluid Flow
Fluid Flow in Porous Media
Seismic waves
Radioactive Decay

Microbes and Plants

Primed Material

Various
$24 \mathrm{hr}$
Not Known

Electromagnetic Induction

Charge Transmission

Charge Transmission

\footnotetext{
(
}

$\begin{array}{ccc}\text { Volcanism } & \text { Not Known } & \text { Not Known } \\ \text { Earthquakes } & \text { Not Known } & \text { Not Known } \\ \text { Earthquakes } & \text { Not Known } & \text { Not Known } \\ \text { Fracture } & \text { Not Known } & \text { Charge Transmission } \\ \text { Materiale Defects } & \text { Not Known } & \text { Charge Transmission } \\ \text { Crystal Lattice Geometry } & \text { Not Known } & \text { Domain Rearrangement } \\ \text { Temperature Gradient } & \text { Not Known } & \text { Charge Transmission } \\ \text { Temperature Gradient } & \text { Not Known } & \text { Domain Rearrangement } \\ \text { Magma Processes } & \text { Not Known } & \text { Charge Transmission } \\ \text { Radioactive Decay } & \text { Not Known } & \text { Charge Transmission }\end{array}$

Table 1. Causes and periods of Earth electricity. GIC are geomagnetically induced currents, TID are traveling ionospheric disturbances, and EM is an abbreviation for the term electromagnetic.

The ongoing diurnal currents are responsible for the corrosion of pipelines and cables in some locations, especially at high latitudes, and have been studied extensively in Scandinavia [Viljanen et al. 2006]. GIC typically are on the order of 200 amperes (A) in man-made conductors, with durations of approximately 10 seconds [Kappenman et al. 1981, Viljanen et al. 1999, Pulkkinen et al. 2008]. The oscillating frequency is typically 0.01 
to $0.001 \mathrm{~Hz}$ [Price 2002]. Peak current can be on the order of $2000 \mathrm{~A}$, and these occur about 10 to 100 times in 100 years [Pulkkinen et al. 2008].

Diurnal flux rates at the sub-auroral latitudes are on the order of a few millivolts per kilometer $\left(\mathrm{mV} \mathrm{km}^{-1}\right)$ [Mather et al. 1964]. The strongest oscillation frequency of these diurnal signals is $0.4 \mathrm{~Hz}$, and is widespread at different latitudes [Mather et al. 1964]. At high latitudes, the motion of charged particles also creates a distinct radio signal, termed the polar chorus, with a characteristic frequency of $300 \mathrm{~Hz}$ to $2 \mathrm{kHz}$ [Barr et al. 2000]. Polar chorus is associated with the solar wind, and the peak intensity is around $50 \mu \mathrm{V} \mathrm{m} \mathrm{m}^{-1}$ as recorded from stations on the ground in Antarctica. It typically exhibits a diurnal variation [Salvati et al. 2000]. Telluric currents (and specifically GIC) were first documented in the 1840 s with the invention of the telegraph. Buried telegraph lines are electrical conductors, and susceptible to electrical induction. Geomagnetically-induced currents caused interference during telegraph transmission, so that the telegraph needles hung frozen by the signals of the GIC. At first this phenomenon was attributed to weather causes, but it was soon recognized that the hung needles coincided with the occurrence of aurora borealis and magnetic storms [Walker 1861].

\subsection{Cosmic-particle flux}

Direct bombardment by high-energy charged particles and radiation coming from solar, stellar, and cosmic sources, act generally to form GIC. For example, a gamma-ray flare from a neutron star 23,000 light years away was reported in 1999 as causing VLF amplitude changes of more than 20 decibels from interaction with the ionosphere. The Lyrid, delta-Aquarid and Perseid metoer showers have caused phase variations in a 16 $\mathrm{kHz}$ signal due to GIC [Barr et al. 2000].

For planetary bodies with no atmosphere, this flux of cosmic particles creates telluric currents directly [Madey et al. 2002]. Cosmic ray ions have an energy flux of about $6 \times 10^{9} \mathrm{eV} \mathrm{cm}^{-2} \mathrm{~s}^{-1}$ for bodies in the Solar System. For Mars, protons and neutrons strike the surface with energy fluxes of around 6000 and $1400 \mathrm{MeV}$ $\mathrm{cm}^{-2}$, respectively [Molina-Cuberos et al. 2001]. This process is not occurring on the Earth's surface at present; the atmosphere intervenes.

\subsection{Planetary magnetic-field plasma}

If ultraviolet and X-Ray emissions from a star encounter a magnetic field, the interactions will create a plasma of energetic electrons. Such a plasma is created in the Earth's magnetosphere from solar radiation, and strikes the moon's surface as it passes through the Earth's magnetotail. as described in Stubbs et al. [2007].
The magnitude of the charging can be several thousand volts [Halekas and Fox 2012]. A magnetotail is the distal part of an oblong magnetic field, caused in this case by the solar wind.

\section{Atmospheric phenomena}

\subsection{Traveling ionospheric disturbances, TID}

Atmospheric compression (i.e. acoustic waves) from a sudden event, such as an earthquake, tsunami, volcanic eruption, severe weather or rocket launches can create traveling ionospheric disturbances (TID) [Georges 1968, Johnston 1997, Afraimovich et al. 2001], and these TID can induce telluric currents in the ground via the geomagnetic field. TID are themselves a category of GIC.

The ionosphere also has resonant electrical phenomena, called Schumann resonances, at a fundamental frequency of $10.6 \mathrm{~Hz}$, with overtones at 18.4, 26.0, 33.5 and $41.1 \mathrm{~Hz}$ [Barr et al. 2000]. The background amplitude of measured Shumann resonances is about 1.0 picoteslas [Schlegel and Füllekrug 1999]. In addition to the above examples, TID can form as the result of gravity waves at the troposphere-ionosphere interface [Georges 1968]. A gravity wave is one where buoyancy or gravity (or both) act to oppose the displacement. A common example of a gravity wave is the wind-generated wave forms one sees at the ocean at the ocean-air interface. Some TID are akin to these, occurring at the troposphere-ionosphere interface. No quantitative reports of the magnitudes of telluric currents resulting from TID are extant, to the best of the author's knowledge, though qualitative magnitudes are known. Space weather events are the strongest TID, and then, in descending order, daytime signals, atmospheric compression events, and gravity waves [Georges 1968].

The effect of TID within the ionosphere is for the disturbance to develop a potential on the order of 1 millivolt per meter [Shiokawa et al. 2003]. Frequency for the ionospheric dynamo region is modeled to be on the order of $10^{-6}$ to $10^{-7} \mathrm{~Hz}$ [Kaladze et al. 2003]. Higher frequencies are also present [Munro 1958]. Short-term changes (on the order of hours) to the Earth's magnetic field may be caused by ionospheric activity. Kaladze et al. [2003] have modeled ionospheric activity that matches the magnitude and timing of ground observations of changes to the geomagnetic field.

The ionosphere is studied with dedicated groundbased facilities, such as the High Frequency Active Auroral Research Program (HAARP) and with satellites. A network of satellites measuring ionospheric disturbances are in place. A 1996 space experiment with a nearly $2 \mathrm{~km}$ long conducting line gathered electrical data in the ionosphere, and then compared these with 
satellite data. The accuracy of modeled ionospheric activity between satellites is low. Modeled electrical data are off by as much 140\% [Szuszczewicz et al. 1998].

On the ground, HAARP has been in operation in Alaska since 1993 [Bailey and Worthington 1997]. That facility is designed to transmit radio-frequency electromagnetic radiation into the ionosphere for communication with submarines, with the electrolytes in the ocean acting as an antenna. HAARP is also suited for ionospheric studies.

HAARP experiments are designed to study the structure of the ionosphere, and for determining practical applications of wave propagation, such as radio signaling. Results have included techniques to produce very low frequency and extremely low frequency (VLF/ELF - $30 \mathrm{~Hz}$ to $30 \mathrm{kHz}$ ) radio waves [Cohen et al. 2008]. Lightning channels broadcast electromagnetic radiation in the VLF range, and HAARP can duplicate this VLF. HAARP has also been used for magnetotelluric surveying.

In a magnetotelluric survey, both electrical and magnetic fields are used for remote sensing, to determine the electrical resistivity of an area, and variations within it, according to an empirical equation

$$
\rho=1 / 5 \mathrm{f}[\mathrm{E} / \mathrm{B}]^{2},
$$

where $\rho$ is the resistivity in ohm meters $(\Omega \mathrm{m}), \mathrm{f}$ is frequency in Hertz $(\mathrm{Hz}), \mathrm{E}$ is the electric field tensor in volts per meter $\left(\mathrm{V} \mathrm{m}^{-1}\right)$, and $\mathrm{B}$ is the magnetic field tensor in nanoteslas (nT) [Wescott and Sentman 2002]. HAARP can generate magnetotelluric signals, and was used as the transmitter for a proof-of-concept controlled-source audio-magnetotelluric survey (CSAMT) in Alaska in 1999 and 2000, prospecting for petroleum [Wescott and Sentman 2002]. This is a new trend. Most magnetotelluric surveys have historically used natural fields [Simpson and Bahr 2005]. Simultaneous measurements of the geomagnetic field and of telluric currents are used to calculate a value for the electrical impedence at depth, to explore subsurface features.

\subsection{Lightning strikes}

Electrical charge is transferred between the ground and the atmosphere during lightning strikes, and the tops of stormclouds close an electrical circuit with the ionosphere. Lightning discharge is energetic and creates plasma that we see. The first pulse of lightning occurs as charges within the cloud consolidate to form a strike leader, and plasma from the ground rises up to meet the leader in that cloud. The next pulse comes from the cloud to the ground. The process repeats, with alternating pulse initiations between ground and cloud. A lightning strike is a combination of about 30 pulse events, each lasting nanoseconds, and its overall duration is on the order of milliseconds [Uman 1994]. The bulk result is a negative charge given to the ground. Peak electric current is $99 \pm 7 \mathrm{kA}$, measured by quantifying remanent magnetization of the ground and calculating the peak magnetic field [Verrier and Rochette 2002]. Oscillation signal frequencies are on the order of $10^{-3} \mathrm{MHz}$ to $10^{3} \mathrm{MHz}$, or higher [Uman and Krider 1982]. The previous data have been normalized to a $10 \mathrm{~km}$ distance, and higher frequency signals are known to attenuate. With some dry lightning and strikes which ignite fires, a positive charge is given from the cloud to the ground. The magnitude of charge carried by positive cloud to ground strikes is increased by the presence of aerosols and smoke [Nichitiu et al. 2009].

\subsection{Lightning-strike induction}

Lightning strikes can also cause transient changes to the geomagnetic field [Verrier and Rochette 2002]. Lightning can occur in various weather conditions, including thunderstorms, dust storms and tornadoes [Barr et al. 2000]. Telluric currents arising from this phenomenon ought to have frequencies of $10^{-3} \mathrm{MHz}$ to $10^{3}$ $\mathrm{MHz}$, based on the ns to ms variations recorded in lightning phenomena. These are the same frequencies that a direct flash of lightning will display. Induction is localized, and portions of large buildings and towers are frequently subject to induction when they are struck. Hussein et al. [2003] compare data from several structures, and the average magnitudes are between 7 and $12 \mathrm{kA}$, with peak magnitudes from 20 to $100 \mathrm{kA}$.

\subsection{Whistler induction}

Lightning discharge heats the air and creates plasma. The entire lightning channel radiates electromagnetic energy. If in the radio frequency, it is called a radio atmospheric signal, or sferic. If the plasma from lightning dishcarge travels along geomagnetic lines, the resulting radio-frequency disturbances are termed "whistlers" and are named for the sound which this interference makes in telephone lines, as first described in 1919 [Schlatter 2008]. The sound was attributed to lightning phenomena in 1953. Whistlers typically occur in the ELF/VLF range of $3 \mathrm{~Hz}$ to $30 \mathrm{kHz}$ [Barr et al. 2000]. For example, observations made from Antarctica at 22.3 $\mathrm{kHz}$ show common changes in amplitude of 3 decibels to an artificially transmitted signal, with duration of around 30 seconds. These changes were associated with whistler activity [Helliwell et al. 1973]. The propogation of whistlers along geomagnetic flux lines can induce changes to local magnetic fields, and these can cause induction of human-made conductors and ore bodies. 


\subsection{Whistler plasma}

Whistlers are caused when plasma from lightning travels along the geomagnetic flux lines. The magnitude of the electron density striking the Earth is on the order of $10^{4}$ electrons per $\mathrm{cm}^{3}$ during whistler events at the equator. Poleward densities should be higher, as the flux lines there are more inclined to the Earth's surface [Schlatter 2008].

\subsection{Volcanic lightning strikes}

An electrical response in the ground as lightning strikes during volcanic eruptions has been described in [Aizawa et al. 2010]. They describe magnetotelluric data from Sakurajima volcano in Kyushu, Japan, from May 2008 to July 2009. Magnetotelluric pulses were recorded coincident with several strikes.

Generally, volcanic plume heights where volcanic lightning has been observed are distributed bimodally: plume heights 1 to $4 \mathrm{~km}$, and plume heights 7 to $12 \mathrm{~km}$. In the former, volcanic lightning is due to vent processes, and in the latter volcanic lightning is due to stratospheric processes [McNutt and Williams 2010]. Occurrence of volcanic lightning increases with height in the stratospheric plumes, and peak currents greater than three thousand amperes have been observed [Bennett et al. 2010]. Ash erupted from a volcano is electrically charged. Whether a circuit is made between charged ash and the ionosphere has not yet been reported. Low frequency ( $30 \mathrm{kHz}$ to $300 \mathrm{kHz}$ ) sferics are reported, as with meteoroligical lightning events, but the emission spectra of the flash itself has not been. Likewise, the author has not found reports of the magnitude of electrical discharge during volcanic lightning.

James et al. [2000] have described a mechanism for ash charging. In a series of experiments, ash-sized particles were ground from several crustal rock samples in a non-conducting sample holder. The materials developed charges of both polarities, generally based on the chemical composition of the particles, with the net charge of $\approx 10^{-5}$ to $10^{-6}$ coulombs per kilogram $\left(\mathrm{C} \mathrm{kg}^{-1}\right)$. Their data are consistent with measurements taken previously within ash fall plumes [James et al. 2000]. They attribute the charge in the ash to fracture-charging, also called fractoemission, where electrical charge is caused in a fracture as electrons are distributed unevenly during fracture processes.

Lightning in volcanic plumes is controlled by topography and wind direction, with negative strikes (negative charge carried to the ground) and positive strikes (positive charge carried to the ground) evolving over the course of an eruption [Hoblitt 1994] or occurring simultaneously. The role of water in the magma and its influence in volcanic lightning is still an open question, though the occurrence of volcanic lightning is not related to latitude, and, hence, is likely not related to the ability of the air to hold water [McNutt and Williams 2010].

\subsection{Storm charging}

Terrestrial electrical fields occur during storm activity. A vertical field on the order of $100 \mathrm{~V} \mathrm{~m}^{-1}$ and a current density at the surface of roughly $2 \times$ $10^{-2} \mathrm{~A} \mathrm{~m}^{-2}$ has been measured during thunderstorm activity, with water droplet interactions in clouds perhaps serving as the source of the initial (negative) charge buildup. These may induce a positive charge in the ground.

In thunderstorm clouds, the negative charge at the bottom of the cloud is offset by a positive charge in the top portion, that together form a conductive circuit flowing upward through the stratosphere, also called a thundercloud cell. In reality, negative charge is flowing downward. The current has been experimentally determined to be around 0.7 A per thundercloud cell [Troshichev et al. 2004]. Current flow in a thundercloud cell accounts for about $96 \%$ of the electrical activity of a storm, while lightning discharges account for a minority $(\approx$ $4 \%)$. Electrical charging of storm clouds is offset by charging of the ocean surface, where daily electrical ocean surface variations are consistent with the daily change of the total area occupied by thunderstorms [Troshichev et al. 2004]. Electrical frequency spectra in the ground from electrostatic storm charging are not reported, to the author's knowledge.

\section{Oceanic phenomena}

\subsection{Electrochemical effects in the ocean}

In the oceans, different layers of water will be stratified by temperature and salinity, and each influences density. Both of these gradients influence electrical conductivity, and create variations in electric currents in the oceans [Chave and Luther 1990]. The signals are low-frequency $(30 \mathrm{kHz}$ to $300 \mathrm{kHz})$ or lower, typically. Voltages from temperature and salinity variations in the ocean are less than a few $\mathrm{mV}$ (silver/silver-chloride electrodes were used) and the differences in salinity and temperature were less than a few parts per thousand and a few degrees Celsius, respectively, between electrodes [Larsen 1992]. The electrode material affects the observed voltage. Internal waves (within the stratified ocean) are measurable electrically in their vertical component as gradients are crossed [Chave 1984]. 


\subsection{Ocean transport induction}

Electrical induction in the oceans occurs by three processes: transport of seawater across the geomagnetic field (treated in this subsection); the influence of GIC on saltwater, a conductor (treated in the subsections above dealing with GIC and TID); and variations in sea water due to variations in salinity and temperature (treated above.) Bulk water transport was first measured electrically by Faraday in 1832, at the Waterloo Bridge with electrodes placed in the Thames River, but sunspot activity (unfortunately) masked the periodic influence of the Gulf Stream [Larsen 1992]. Induced voltage due to transport of saline water has been observed successfully, with a magnitude on the order of $25 \mathrm{mV}$ per kilometer, measured on a cable fitted with electrodes in the Straits of Florida [Larsen 1992]. The GIC (with peaks up to about $50 \mathrm{mV} \mathrm{km}^{-1}$ but with typical values of 10 to 20 $\mathrm{mV} \mathrm{km}^{-1}$ ) had been subtracted out of the data by hand. The voltages occur at frequencies from $10^{-3.8}$ to $10^{-7.0}$ $\mathrm{Hz}$ and are incomplete, and tidal variation and other outliers create peaks around $10^{-5} \mathrm{~Hz}$.

\subsection{Oceanic charging}

Two sources of electric currents in the ocean already described in this text are: storm clouds charging the ocean surface (above); and processes to charge water strata in the ocean itself. Electricity from both of these may be transmitted to the rock with which it is in contact via electrostatic induction [Cox 1981]. The oceanic lithosphere receives a quasi-static charge from the ocean. Due to the high metal content of the rock, both electrostatic and electromagnetic induction will occur if major changes to electric current in the oceans or to the geomagnetic field also occur.

\subsection{Metabolic electrochemistry in the ocean}

The metabolic action of micro- and macrobiota in the oceans may contribute to an electrical signal that is measurable. Bohlin et al. [1989] describes how fish are attracted to electric signals; this phenomenon might be related either to physiology or to food sensing. Brahic [2010] describes how an extensive network of microbial electric currents may exist in oceanic mud. Atekwana and Slater [2009] introduce the study of microbial geophysical signatures in a comprehensive manner; biogeophysics is an emerging field, and more research is warranted.

\section{Surface phenomena}

\subsection{Artificial signals}

Earth electric currents may come from the transmission of electricity or electromagnetic radiation em- anating from human-made sources [Keller 1968, Pham et al. 1998] and also from on-ground activity, such as from electric trains. Telluric currents may come from electrical fields set up intentionally as, for example, from a direct-current (DC) electrical field designed to remove contaminants from soils [Probstein and Hicks 1993]. Electroremediation can be accomplished with a field strength of about $150 \mathrm{~V} \mathrm{~m}^{-1}$. A complexing agent is added to the groundwater, and contaminants are attracted to wells for removal [Wong et al. 1997].

The magnitude of artificial telluric currents depends directly upon the generation process. Extremely low frequency radio waves are generated by heating the ionosphere, and are used by the US military to communicate with submarines, for example. Nuclear explosions above ground also create ionospheric VLF radiation, with frequencies of $10 \mathrm{kHz}$ to $15 \mathrm{kHz}$ [Barr et al. 2000].

\subsection{Metabolic electrochemistry in soil}

The daily action of plants, fungi, bacteria, lichen or algae that inhabit soil and rock fissures may produce electrical signals from electrochemical processes related to metabolism. Some evidence exists that soil microbes respond to changes in the geomagnetic field [Jie Li et al. 2009], though the converse has not been shown. Abdel Aal et al. [2010] report that the imaginary component of measured conductivity in sand is increased linearly as Pseudomonas aeruginosa are introduced to the grains. The imaginary component of conductivity is a measure of its dissipation, part of the field equations that model oscillating or alternating current. Abdel Aal et al. [2010] used low frequency $(0.1$ to $1000 \mathrm{~Hz})$ signals for their study. No change to the real component of the conductivity was observed.

Regarding plants: despite the existence of diurnal electrical variations measured in sapwood [Gilbert et al. 2006], and in leaves and leaf stems [Gil et al. 2008], and also despite the invention of functional electrical circuitry powered by plants and trees [Himes et al. 2010, Yamaguchi and Hashimoto 2012], no diurnal soil-root signal from plants has been detected [Love et al. 2008]. A new sensor for these signals has recently been developed [Gurovich 2009], but no evidence of diurnal signals has been published yet.

\subsection{Exo-electron emission}

The process of stress relaxation may release electrons after an initial priming, as can the addition of heat or photons to a previously stressed sample [Oster et al. 1999]. These and related processes are termed exo-electron emission if the energy of the electrons is low (less than or equal to one electron volt), to distinguish it from high-energy electron emission phenomena, such as frac- 
toemission. Exo-electron emission functions by means of traps and defects and requires a solid-gas or solid-vacuum interface for its action: it acts at a surface. Exo-electron emission may occur in the vadose zone or on the surface of the crust [Oster et al. 1999, Freund 2011]. Exoelectron flux is observed as less than or equal to $10^{8}$ electrons (e-) per square centimeter [Oster et al. 1999].

\section{Groundwater phenomena}

\subsection{Electrochemical effects in groundwater}

As ionically-charged fluids travel in porous rock, an electric current is created by the motion of the suspended ions [Corwin and Hoover 1979]. This is the principle behind household chemical batteries, and is common in nature. The electrochemical effect found in ore bodies, for example, is akin to commercial electrochemical batteries in magnitude (a few volts) [Lile 1996]. While the chemistry of the fluid determines the voltage, the signal frequencies are controlled by the motion.

\subsection{The electrokinetic effect}

Just as the motion of ionically-charged fluids in porous rock creates an electrochemical current, so too the interaction of the charged fluid with the bounding rock creates a complementary charging in the rock itself. At the fluid-rock interface, a single layer of adsorbed ions attracts a second layer of the opposite sign, and these are sufficient to create an electrical potential over a distance. This so-called streaming potential, caused by an electrokinetic effect, involves electrostatic induction by moving ions. Self potential is a combination of streaming potential (based on the electrokinetic effect) and of the diffusion of the ions themselves.

Typically, self potential is present in groundwater flows [ Aubert and Atangana 1996, Birch 1998, Revil et al. 2003, Jardani et al. 2006], but can also be found in many geologic settings, such as sulphide ore bodies [Lile 1996] and other mineral deposits, including graphitic deposits [Stoll et al. 1995], and on volcanoes, where the phenomenon is due to hydrothermal activity, changes in groundwater flow, and magma displacement [Zlotnicki and Nishida 2003]. In hydrothermal settings, streaming potential from electrokinetic effects is much stronger than associated thermoelectric effects [Corwin and Hoover 1979]. A streaming potential of up to $30 \mathrm{mV}$ can be generated from a groundwater change of $50 \mathrm{~cm}$, if the fluid resistivity is $10^{2} \Omega \mathrm{m}$ and the rock permeability is $10^{-12}$ $\mathrm{m}^{2}$ [Jouniaux and Pozzi 1995]. Streaming potential variations occur, with pulses in amplitude of 15 to 40 $\mathrm{mV}$, and a frequency of 0.1 to $0.5 \mathrm{~Hz}$ [Jouniaux and Pozzi 1997].

\subsection{Seismic-dynamo induction}

Rock is displaced as seismic waves pass through. Groundwater in the pore space is displaced as well, as are ions in the groundwater. The motion of ions relative to the geomagnetic field creates circularly or elliptically polarized electric fields, with opposite orientations for positive and negative ions. This effect was reported in 2009, and was observed both for artificial seismic waves from blasting and for natural seismic waves [Honkura et al. 2009]. The magnitude of the seismic-dynamo effect is on the order of $\mu \mathrm{V}$ to $\mathrm{mV}$, and frequency depends upon the ions in the groundwater, with observed values between approximately 10 and $50 \mathrm{~Hz}$.

Cyclotron frequency is the name given for charged particles moving in circular motion perpendicular to a magnetic field. Each charged particle has a cyclotron frequency based on its charge, mass and velocity relative to the magnetic field. The observed seismic-dynamo effect reported in Honkura et al. [2009] shows electric frequencies that may be interpreted as resonances of the cyclotron frequency of particles and the geomagnetic field, with bicarbonate, chloride, sodium and calcium taken as constituents. These vary in abundance by location, and account for differences of orientation in the observed electric fields.

\subsection{Radioactive ionization}

Radionuclides release energy as they decay, and that energy can ionize surrounding material. Radon gas is one example. The most common isotope of radon $\left.{ }^{222} \mathrm{Ra}\right)$ has a half-life of 3.8 days [Jordan et al. 2011]. Several thousand scientific publications have described the presence of radon as co-seismic with major events. Radon at the Earth's surface ionizes particles in the air, and the motion of these ions creates atmospheric electrical phenomena linking the surface to the ionosphere [Pulinets 2007]. Co-seismic ionospheric anomalies might be attributed to the action of ions created as radon is released. Studies of radon occurrence as an earthquake precursor often look for radon concentrations in groundwater [Jordan et al. 2011]. It is plausible to assume that radon ionizes other atoms in groundwater, and that the motion of these ions can create an electric signal. Other radionuclides could do the same.

\section{Other terrestrial phenomena}

\subsection{Volcanic electromagnetic signals}

Hata et al. [2001] report detection of consistent electromagnetic signals during the Izu-Miyake volcanic eruption of 2000 in Japan. The signals preceded the eruption by a week, and were associated with changes to the surface of the Earth from magma dike growth. 
The exact mechanism of the signal generation is unknown. The observational apparatus was set to detect extremely low frequency radio waves (between $10 \mathrm{~Hz}$ and $300 \mathrm{~Hz}$ ). Below $10 \mathrm{~Hz}$, ionospheric and other geomagnetic signals predominate, and above $300 \mathrm{~Hz}$, lightning noise predominates. The full spectrum of the occuring radiation is not known.

\subsection{Seismic electromagnetic signals}

Matsumoto et al. [1998] report television signal interference associated with the 1995 Kobe earthquake in Japan. The electromagnetic radiation preceded the earthquake by 6.5 hours, and was characterized as having a magnitude of a few tens of $\mathrm{mV} \mathrm{m}^{-1}$, a frequency in the $217 \mathrm{MHz}$ range with microsecond duration. Other reports of electromagnetic phenomena during earthquakes are common, typically involving ionospheric disturbances [Davies and Baker 1965, Pulinets and Boyarchuk 2004, Popov et al. 2004, Singh and Singh 2007, Pulinets 2007, Perrone et al. 2010, Heki 2011, Zolotov et al. 2012].

\subsection{Seismic electric signals}

Three types of signals have been reported from a network of monitoring stations in Greece [Varotsos et al. 1993]. First, a gradual variation in the electric field of the Earth (GVEF) has been recorded, on the order of weeks or more before an earthquake, and with voltage an order of magnitude higher than other purported precursory SES. These occur rarely. Second, presumed seismic electric signals, on the order of hours to 11 days before an earthquake, with an order of magnitude in the millivolt range, occur commonly. Third, a short duration pulse, 1 to 4 minutes precedent to seismic waves, with an order of magnitude in the volt range, occur rarely [Ralshovsky and Komarov 1993, Varotsos et al. 1993]. All three are low-frequency signals, less than or equal to $1 \mathrm{~Hz}$ [Varotsos et al. 2011]. Similar seismic signal data have been reported in Japan using the same method [Uyeda et al. 2009].

\subsection{Fractoemission}

Fractoemission, in which electrons escape from a freshly cleaved surface, has been described in James et al. [2000]. Their observations show electrical charging of about $10^{-5}$ coulombs per kilogram for volcanic ash. Fracture experiments have recorded up to 10 parts per million ( $\mathrm{ppm}$ ) ozone production from the crushing of typical terrestrial crustal rock, with the ozone being generated by electricity from physical charge separation during fracture [Baragiola et al. 2011] The energy of the emitted electrons can be very high, up to tens of thousands of electron volts $(10 \mathrm{keV})$ or higher. The elec- trons are produced as the surface attains and maintains a charge, often pulling electrons from deep inside, termed the Malter effect [Oster et al. 1999]. Electromagnetic emission resulting from a single crack in ice under various stress regimes has a frequency of $10^{3}$ to $10^{5} \mathrm{~Hz}$, with a change in potential of about $2 \mathrm{mV}$ [Shibkov et al. 2005].

\subsection{Defect charging}

Pressure can cause defects in materials. Defects can both liberate charge carriers, such as ions or electrons, and create charge acceptors, such as holes or lattice vacancies. Pressure changes can also result in the reorientation and charging of lattice defects, called defect charging. These processes have characteristic electromagnetic emissions, with frequencies in the range $10^{2}$ to $10^{6} \mathrm{~Hz}$ for crystals with predominantly ionic bonds [Shibkov et al. 2005].

Defect charging has been studied as a candidate for the cause of electrical signals associated with earthquake phenomena [Varotsos et al. 1998, Freund 2011]. Takeuchi and Nagao [2013] demonstrate an electromotive force of $80 \mathrm{mV}$ in gabbro with $50 \mathrm{MPa}$ of load. Freund [2011] proposes that peroxy defects present in silicate rocks, where the tetrahedral silicate bonds are $\mathrm{O}_{3} \mathrm{Si}-\mathrm{OO}-\mathrm{SiO}_{3}$ instead of $\mathrm{O}_{3} \mathrm{Si}-\mathrm{O}-\mathrm{SiO}_{3}$, can be a source of mobile charge carriers. Peroxy bonds commonly break under pressure. The new structure can accept an electron from a neighboring silica-oxygen tetrahedron. That transfer, in turn, creates a positive hole in the electron donor. Positive holes can also interact with negative ions liberated from the lattice by changes in pressure, e.g. from seismic waves. This condition may form paths for electric current to flow.

Such defect phenomena are fundamental to how semiconducting materials work, and are probably widespread in nature. General terms for the process described above are "charge-vacancy coupling" or "defect and charge transport" [Raymond and Smyth 1996]. Peroxy bonds exist in silicate rocks in enough numbers to create measurable electricity. The process of charge-vacancy coupling is nontrivial in all rocks, given the right conditions. Typical electric currents from defect charging in rock are on the order of 1 nanoampere at 20 megapascals of pressure [Freund 2011].

\subsection{The piezoelectric effect}

The piezoelectric effect (electric field or charge caused by applied pressure) has been modeled as a crystal lattice effect, as deformation from stress or strain displaces the positions of shared electrical bonds [Cady 1946, Mason 1950]. This is the mechanism first described by Voigt [Voigt 1910, Katzir 2006]. Stress is an 
internal pressure of particles acting on each other, caused by external load. Strain is a change to the shape of a material, caused by stress. Piezoelectricity is based on the symmetry of a crystal.

A more in-depth treatment of the ideas in the following paragraph can be found in Sands [1994]. Crystals can have three types of symmetry. If the coordinates of a crystal lattice are hypothetically reflected through a point, a new inverse lattice with new inverse coordinates is created. If the inverse lattice is identical to the original crystal lattice, the crystal is centrosymmetric. If the inverse lattice is not identical to the original crystal lattice, but the inverse lattice can be rotated to match the original lattice, then the crystal is non-centrosymmetric. If the inverse lattice is not identical to the original crystal lattice, and the inverse lattice cannot be rotated to match the original lattice, then the crystal is chiral, also called enantiomorphic. The terms "chiral" and "enantiomorphic" are synonyms and refer to handedness. These crystals occur in both left-handed and right-handed forms.

For a more in depth treatment of the following descriptions of piezoelectricity, see Cady [1946]. A centrosymmetric crystal lattice ought not allow for any electrical charge to build up under pressure. Every bond displaced will be countered by another bond whose displacement can cancel the charge of the first. However, some minerals with centrosymmetric crystal lattices, such as zeolites and topaz, express electricity under stress and strain. No explanation has yet been proposed for this anomaly.

Many chiral and non-centrosymmetric minerals display the piezoelectric effect. The most well-known is quartz, and the most intuitive application at one time was in record needles or microphones, to change variations in pressure into an electrical signal. The electrical signals in these devices are very small, on the order of $10^{-12}$ coulombs per newton $\left(\mathrm{C} \mathrm{N}^{-1}\right)$ for a single crystal. Piezoelectric data for some minerals can be found in SpringerMaterials, an online version of the LandoltBörnstein Database [SPRINGER 2012].

\subsection{The thermoelectric effect}

A homogeneous conductor expresses a voltage when there is a temperature gradient, with electrons (the more negative) at the cold end. This is called the Seebeck effect (or the thermoelectric effect), and is directly observable as electric current when two dissimilar conductors are connected to each other under a thermal gradient [Goupil et al. 2011]. Thermocouples are based on this effect. For more information on the following discussion, see von Baeckmann et al. [1997]. Corrosion of bridges and other metal structures where dissimilar metals are found is caused by this phenomenon. In the crustal materials of the Earth, the thermoelectric effect is important in ore bodies, and in regions with high heat flux. The magnitude is on the order of $10^{-5}$ volts per degree Kelvin [SPRINGER 2012].

Geologic case studies are abundant. Shankland [1975] describes measurements of thermoelectricity from rock samples in a laboratory setting. Leinov et al. [2010] describe thermoelectric effects in brine-saturated sandstone in situ. The thermoelectric effect from ore minerals, for example from pyrite during computeraided resistivity surveys for gold (called pyrite-thermoelectric surveying), has also been described [Cao Ye et al. 2008, Zhang Yun-qiang et al. 2010], as has thermoelectricity from magnetite grains in the Earth's crust, and especially in the middle-lower crust [Junfeng Shen et al. 2010]. This widespread effect is similar to defect charging (described in the Defect charging subsection, above) in that both processes mobilize charge carriers and holes (acceptors), the one with a temperature gradient, the other with pressure.

Note that both of the temperature effects listed in this section (i.e. the thermo-and pyroelectric effects) have sometimes been lumped together as the thermoelectric effect. They have been described as such by Corwin and Hoover [1979], who treat temperature effects as unwanted signal noise in self potential surveying. They are unwanted if one is looking for electrical indications of water flow (from the motion of ion-rich water, and from the electrokinetic effect) for geothermal use.

\subsection{The pyroelectric effect}

Water is a polar molecule. Any material whose structure has an axis with dissimilar ends, and whose ends are of uneven electrical charge, is a polar material. The dissimilar ends are called a permanent electric dipole. In polar minerals, electric charges located at the ends of the permanent electric dipole are rapidly neutralized by the environment under normal conditions. During heating or cooling, however, the charges do not have time to dissipate, and are detectable. This phenomenon is called pyroelectricity, or the pyroelectric effect [Bhalla et al. 1993]. It is sensitive to both the change in temperature and the rate of change in temperature of a polar material. Tourmalines are common minerals that exhibit this effect [Hawkins et al. 1995]. Typical magnitudes are on the order of $10^{-6}$ coulombs per square meter per Kelvin for single crystal samples.

\subsection{Magma electrochemistry}

The motion of magma during volcanic processes and also of volatiles can hypothetically create an elec- 
tric signal. Volatiles can in some instances ionize surrounding materials, and magma itself can be rich with ions. No study of these natural electrical phenomena is found in the literature, to the author's knowledge. Toramaru and Yamauchi [2012], in trying to create an analog to layered dikes and sills, used an externally applied electric field to create cyclically-layered structure in an artificial material, $\mathrm{PbI}_{2}$.

\subsection{Radioactive emission}

Electric current can hypothetically be caused directly by the motion of charged particles released by the breakdown of radionuclides. For example, $\alpha$-particle emission is a steady source of charged particles, and therefore creates an electric signal. Significant radioactive decay has been reported in natural fission reactors as having occurred in the past [Gauthier-Lafaye 1997, Jensen and Ewing 2001, Stille et al. 2003]. Electrical observations of this phenomenon are not in the published literature, to the author's knowledge.

\section{Deep terrestrial phenomena}

\subsection{Geomagnetic jerk}

Short-term changes to the second derivative of the geomagnetic field are termed geomagnetic jerks, and arise from electrical signals traveling through the mantle during deep (core) events [Nagao et al. 2003]. Transmission of electricity from the upper mantle to the lower crust is likely, but has not been observed. Separate geomagnetic jerks of limited extent have been modeled as having been caused by single events originating in and traveling through Earth's core, as described in Chulliat et al. [2009]. The physical models suggest that quantifying mantle conductivity is still an open question [Malin and Hodder 1982].

The electrical conductivity of the deep mantle is two orders of magnitude higher than that of the shallow mantle, with a transition depth of $670 \mathrm{~km}$. Another region of higher conductivity transition occurs at $2700 \mathrm{~km}$, the D" layer, so named as part of Keith Bullen's Earth taxonomy from the 1940s [Chao 2000, Constable and Constable 2004, Duffy 2008, Ohta et al. 2008]. The increased conductivity has been modeled using a combination of proton conduction if hydrogen is present and polaron conduction, which is electron hole hopping between $\mathrm{Fe}^{2+}$ and $\mathrm{Fe}^{3+}$ ions in minerals that contain iron [Yoshino 2010]. Both of these are semiconductor phenomena. A wet mantle is not generally required to fit the observations [Yoshino et al. 2008]. The increase at the D" layer is also related to the transition from perovskite, an orthorhombic mineral, to post-perovskite, a sheet mineral, that occurs at this depth [Duffy 2008].

Bulk rock responses to local changes in the geomagnetic field caused by changes in the Earth's core ought to affect ore bodies or other rock with high conductivity. No articles are apparently available that report long-term telluric currents caused by fluctuations in the geomagnetic field originating in the Earth's core.

\section{Producing electricity}

Several models depict electricity-generation processes. Four of these are useful in conjunction with the study of telluric currents. These are listed in Table 3, with a brief explanation for each.

Charged particles, if they change location, transfer charge. Charged particles, such as electrons or ions, are termed charge carriers. The motions of ions or electrons are examples of the direct transfer of electric charge.

A deeper treatment of the ideas in the following description may be found in Jonassen [2002]. Electrostatic induction is a special case of charged particle transfer. An external charge elicits an electrical response from a second material containing mobile charge carriers. The charge carriers move to neutralize the applied field. If the external charge is positive, for example, then negative charge carriers will migrate within the second material to the site of the external charge. This model is termed electrostatic induction because the charge transfer is induced within one of the materials, but no charge is transferred between them.

A more thorough treatment of the ideas in the following description may be found in Schieber [1986]. Electromagnetic induction occurs in any electrical conductor where a change in a magnetic field occurs, so that the magnetic flux lines pass through the conductor. The combination of mobile charge carriers and magnetic flux creates an electromotive force. This is the principle behind electrical power generation, for example. A coil of wire moves through a magnetic field, and the motion creates electric current in the wire. Electricity is generated.

If the charge carriers in a material are not mobile, electricity can be generated by deformation of the material, or some other process that changes the configuration of the domains carrying electric charge. The rearrangement of electrical domains can generate electricity.

\section{Monitoring telluric currents}

The geomagnetic field is currently monitored by an extensive network of government-run observatories and includes a near-real-time international data repository [Kerridge 2001, INTERMAGNET 2012]. The same is not the case for Earth's telluric phenomena, but some 


\begin{tabular}{|c|c|c|c|}
\hline Name & Magnitude & Duration & Frequency \\
\hline Lightning Strikes & $10^{5} \mathrm{~A}($ peak $)$ & $1 \mathrm{~ms}$ & $10^{-3}$ to $10^{3} \mathrm{MHz}$ \\
\hline Lightning Strike Induction & $10^{5} \mathrm{~A}$ (peak) $/ 10^{4} \mathrm{~A}$ & $1 \mathrm{~ms}$ & $10^{-3}$ to $10^{3} \mathrm{MHz}$ \\
\hline Volcanic Lightning Strikes & $>3 \mathrm{kA}($ peak $)$ & Not reported & Not reported \\
\hline Artificial Signals & Various & Various & Various \\
\hline \multirow[t]{4}{*}{ GIC (Space Weather) } & 200 A (metal) & $\approx 10 \mathrm{~s}$ & $10^{-3}$ to $10^{-2} \mathrm{~Hz}$ \\
\hline & $50 \mu \mathrm{V} \mathrm{m}^{-1}$ (chorus) & Various & $300 \mathrm{~Hz}$ to $2 \mathrm{kHz}$ \\
\hline & Not reported ( $\gamma$-rays) & Various & VLF \\
\hline & Not reported (meteors) & Various & $16 \mathrm{kHz}$ \\
\hline Planetary Magnetic Field Plasma & $5000 \mathrm{~V}$ (Lunar surface) & $\approx 1$ week & Not reported \\
\hline Storm Charging & $10^{-2} \mathrm{~A} \mathrm{~m}^{-2}$ & hrs to days & Not reported \\
\hline Electrochemical Effetcs & $5 \mathrm{~V}$ & Various & $<300 \mathrm{kHz}$ (ocean) \\
\hline Electrokinetic Effects & $100 \mathrm{mV} \mathrm{km}^{-1}$ & Ongoing & 0.1 to $0.5 \mathrm{~Hz}$ \\
\hline Ocean Transport Induction & $25 \mathrm{mV} \mathrm{km}^{-1}$ (metal) & Ongoing & Some from $10^{-7.0}$ to $10^{-3.8} \mathrm{hz}$ \\
\hline GIC (Diurnal) & $1 \mathrm{mV} \mathrm{km}^{-1}$ (ionosphere) & $\approx 1 \mathrm{~d}$ & $0.4 \mathrm{~Hz}$ \\
\hline Cosmic Particle Flux & $6000 \mathrm{MeV} \mathrm{cm}^{-2}$ (Mars) & Various & Not reported \\
\hline Whistler Plasma & $10^{4} \mathrm{e}-\mathrm{cm}^{-3}$ (surface) & Not reported & Not reported \\
\hline Seismic EM Signals & $\approx 20$ to $50 \mathrm{mV} \mathrm{m}^{-1}$ & $\approx 1 \mu \mathrm{s}$ & $217 \mathrm{MHz}$ \\
\hline Fractoemission & $10^{-5} \mathrm{C} \mathrm{kg}^{-1}$ (ash) & Various & $10^{3}$ to $10^{5} \mathrm{~Hz}$ (ice) \\
\hline Seismic Electric Signals & 1 to $10 \mathrm{mV}$ & Various & $\leq 1 \mathrm{~Hz}$ \\
\hline Seismic Dynamo Induction & $\mu \mathrm{V}$ to $\mathrm{mV}$ & Various & 10 to $50 \mathrm{~Hz}$ \\
\hline Thermoelectric Effects & $10^{-5} \mathrm{~V} \mathrm{~K}^{-1}$ & Ongoing & Not reported \\
\hline Pyroelectric Effects & $10^{-6} \mathrm{C} \mathrm{m}^{-2} \mathrm{~K}^{-1}$ (single crystal) & Ongoing & Not reported \\
\hline Defect Charging & $10^{-9} \mathrm{~A}$ & Various & $10^{2}$ to $10^{6} \mathrm{~Hz}$ \\
\hline Exo-Electron Emission & $\leq 10^{8} \mathrm{e}-\mathrm{cm}^{-2}$ & Various & Not reported \\
\hline Volcanic EM Signals & 1 to $5 \mathrm{pT}$ & Various & Radio frequencies \\
\hline TID (Schumann Resonances) & $1.0 \mathrm{pT}$ & Ongoing & $10.6,18.4,26.0,33.5$, and $41.1 \mathrm{~Hz}$ \\
\hline Geomagnetic Jerk & Not reported & Ongoing & Not reported \\
\hline Magma Electrochemistry & Not reported & Ongoing & Not reported \\
\hline Radiaoctive Emission & Not reported & Not reported & Not reported \\
\hline Radioactive Ionization & Not reported & Not reported & Not reported \\
\hline Oceanic Charging & Not reported & Ongoing & Not reported \\
\hline TID (Compressive Event) & Not reported & Various & Not reported \\
\hline TID (Gravity Wave) & Not reported & Ongoing & $10^{-7}$ to $10^{-6} \mathrm{~Hz}$ \\
\hline Whistler Induction & Not reported & $\approx 30 \mathrm{~s}$ & $10 \mathrm{~Hz}$ to $30 \mathrm{kHz}$ \\
\hline Metabolic Electrochemistry & Not reported & Not reported (Hypothetical) & Not reported \\
\hline
\end{tabular}

Table 2. Magnitude, duration and transmission frequency of Earth electricity, arranged by magnitude. GIC are geomagnetically induced currents, TID are traveling ionospheric disturbances and e- is electrons.

\section{Model}

Direct Transfer of Charge

Electrostatic Induction

Electromagnetic Induction

Rearrangement of Electrical Domains

\section{Explanation}

Charge carriers such as ions or electrons change location, and their motion transfers electric charge

External electric charge creates an electromotive force within a material as particles move to neutralize the external charge

Relative motion of a magnetic field creates an electromotive force on electric charge carriers within it

Deformation creates electricity as it changes the position of immobile charge carriers in a material

Table 3. Electricity-generation models. 
national institutions and systems are in place and usually produce freely-available data. China, Russia, South Africa, Japan, Greece, the United States and Canada, for example, all have networks of magnetotelluric stations to monitor seismic events as they sometimes correlate with electrical and magnetic signals. References or websites exist for China [Xuhui Shen et al. 2011], Russia [ISTP SB RAS 2012], South Africa [Fourie 2011, FACEBOOK 2012], Japan [Kawase et al. 1993, Uyeshima et al. 2001, Geospatial Information Authority of Japan 2010], Greece [Varotsos et al. 1993], and the U.S. and Canada [Zhdanov et al. 2011, Incorporated Research Institutions for Seismology 2012]. No global correlation network of electric signal data exists in real time, though the MTNet, maintained by a working group of the International Association of Geomagnetism and Aeronomy will perhaps assume this role [MTNET 2012]. This association houses research results and data, acts as an international forum, and hosts workshops and conferences. Likewise, a working group of the International Union of Geodesy and Geophysics (IUGG) hosts conferences and workshops on Electromagnetic Studies of Earthquakes and Volcanoes [EMSEV 2013], and they may have a strong interest in creating this type of network.

\section{Discussion}

Thirty-two distinct causes of telluric currents have been listed above. Here are some highlights that might serve to promote further research. These have been selected as affecting either public health, the economy, or human progress.

- Lightning phenomena, GIC, TID and the thermoelectric effect are mechanisms that have been of the greatest interest to society, since these can disrupt communications or destroy structures and equipment. Except for lightning, these act via corrosion, and are slow.

- The references to self-potential and the electrokinetic effect may deserve more interest, especially the work out of China, looking at sulfide ores and gold. Rare earth elements also seem to be of strategic economic and political importance.

- Seismic electric phenomena may have immense practical applications for public safety. Distinguishing between purported seismic electric signals and other electrical events might allow for successful earthquake forecasting.

- The papers on using plant metabolism to power circuits and batteries may be of interest for alternative energy research. Harnessing plants directly for electricity would attack anthropogenic climate change on two levels: by providing carbon sequestration and energy production.
It is hoped that there will be more progress in these areas, and that Tables 1 and 2 will be critically assessed and added to. Electrical energy is one of the hallmarks of life, and of space. It is critical for the transfer of information, as well. As more of human culture takes advantage of electronic media, it seems logical and benign to extend human knowledge of electricity in the Earth itself. For example, remote sensing is now available for our homes, and we can turn on lights in a room just by moving towards it. How much more important is it, now, to build a more complete system of remote sensing for our global home, the Earth, and its environs?

Missing from this study is a thorough review of data related to the electrical conductivity of the various features of the lithosphere, and the connection between resistivity and rock types, tectonic regimes, seismic activity, geochemistry, and similar geologic parameters. Such a review would likely be fruitful.

Acknowledgements. No funding was received for this project, which was completed as part of a Masters thesis on metamorphism and electrical phenomena in the Earth's crust at California State University Long Beach. Thank you Oleg Zolotov of EMSEV for constructive criticism related to storm charging, and to Roswitha Grannell, Andreas Bill, Jack Green and Ewa Burchard of CSULB for editorial comments. Love always to my parents.

\section{References}

Abdel Aal, G.Z., E.A. Atekwana, S. Rossbach and D.D. Werkema (2010). Sensitivity of geolelectrical measurements to the presence of bacteria in porous media, J. Geophys. Res., 115, G03017; doi:10.1029/ 2009JG001279.

Afraimovich, E.L., E.A. Kosogorov, N.P. Perevalova and A.V. Plotnikov (2001). The parameters of shock acoustic waves generated during rocket launches, Adv. Space Res., 27, 1339-1343.

Aizawa, K., A. Yokoo, W. Kanda, Y. Ogawa and M. Iguchi (2010). Magnetotelluric pulses generated by volcanic lightning at Sakurajima volcano, Japan, Geophys. Res. Lett., 37, L17301; doi:10.1029/2010GL04 4208.

Atekwana, E.A., and L.D. Slater (2009). Biogeophysics: A new frontier in Earth science research, Rev. Geophys., 47, RG4004; doi:10.1029/2009RG000285.

Aubert, M., and Q.Y. Atangana (1996). Self-potential method in hydrogeological exploration of volcanic areas, Ground Water, 34, 1010-1016.

Bailey, P.G., and N.C. Worthington (1997). History and application of HAARP technologies: The High Frequency Active Auroral Research Program in Proceedings, Intersociety Energy Conversion Engineering Conference, IECEC-97, 32nd, (2), 1317-1322.

Baragiola, R., C.A. Dukes and D. Hedges (2011). Ozone 
generation by rock fracture: Earthquake early warning?, Appl. Phys. Lett., 99, 204101; doi:10.1063/1.366 0763.

Barr, R., D. Llanwyn Jones and C.J. Rodger (2000). ELF and VLF radio waves, J. Atmos. Sol. Terr. Phys., 62, 1689-1718.

Bennett, A.J., P. Odams, D. Edwards and P. Arason (2010). Monitoring of lightning from the April -May 2010 Eyjafjallajökull volcanic eruption using a very low frequency lightning location network: Environ. Res. Lett., 5, 044013; doi:10.1088/1748-9326/5/4/04 4013.

Bhalla, A.S., W.R. Cook Jr. and S.T. Liu (1993). Low frequency properties of dielectric crystals: Piezoelectric, pyroelectric and related constants in LandoltBörnstein Numerical Data and Functional Relationships in Science and Technology, New Series, Group III: Condensed Matter: Crystal and Solid State Physics, Volume 29b, O. Madelung (editor), Berlin, Springer-Verlag, 554 pp.

Birch, F.S. (1998). Imaging the water table by filtering self-potential profiles, Ground Water, 36, 779-782.

Bohlin, T., S. Hamrin, T.G. Heggberget, G. Rasmussen and S.J. Saltveit (1989). Electrofishing - Theory and practice with special emphasis on salmonids, Hydrobiologia, 173, 9-43.

Boteler, D.H., R.J., Pirjola and H. Neyanlinna (1998). The effects of geomagnetic disturbances on electrical systems at the Earth's surface, Adv. Space Res., 22, 17-27.

Brahic, C. (2010). The real Avatar: Ocean bacteria act as "superorganism", New Scientist, 205, 11.

Cady, W.G. (1946). Piezoelectricity: An Introduction to the Theory and Applications of Electromechanical Phenomena in Crystals, New York, McGraw-Hill, $822 \mathrm{pp}$.

Cao Ye, Li Sheng-rong, Ao Chong, Zhang Hua-feng, Li Zhen-zhen and Liu Ziao-bin (2008). Application of thermoelectric properties of pyrite in gold exploration in the Shihu gold deposit, western Hebei, Geology in China, 04, http:/ / en.cnki.com.cn/Jour nal_en/A-A011-DIZI-2008-04.htm (May 2012).

Chao, B.F. (2000). Renaming D double prime: Forum: Eos, Trans. Amer. Geophys. Union, 81, 46.

Chave, A.D. (1984). On the electromagnetic fields induced by oceanic internal waves, J. Geophys. Res., 89, 10519-10528.

Chave, A.D., and D.S. Luther (1990). Low-frequency, motionally induced electromagnetic fields in the ocean, J. Geophys. Res., 95, 7185-7200.

Chulliat, A., E. Thébault and G. Hulot (2009). Core field acceleration pulse as a common cause of the 2003 and 2007 geomagnetic jerks, Geophys. Res. Lett., 37,
L07301; doi:10.1029/2009GL042019.

Cohen, M.B., U.S. Inan and M.A. Golkowski (2008). Geometric modulation: A more effective method of steerable ELF/VLF wave generation with continuous HF heating of the lower ionosphere, Geophys. Res. Lett., 35, L12101; doi:10.1029/2008GL034061.

Constable, S., and C. Constable (2004). Observing geomagnetic induction in magnetic satellite measurements and associated implications for mantle conductivity, Geochem. Geophys. Geosyst. 5, Q01006; doi:10.1029/2003GC000634.

Corwin, R.F., and D.B. Hoover (1979). The self-potential method in geothermal exploration, Geophysics, 44, 226-245.

Cox, C.S. (1981). On the electrical conductivity of the oceanic lithosphere, Phys. Earth Planet. In., 25, 196201.

Davies, K., and D. Baker (1965). Ionospheric effects observed around the time of the Alaskan earthquake of March 28, 1964, J. Geophys. Res., 70, 2251-2253.

Diodati, P., S. Piazza, A. Del Sole and L. Masciovecchio (2001). Daily and annual electromagnetic noise variation and acoustic emission revealed on the Gran Sasso mountain, Earth Planet. Sci. Lett., 184, 719-724.

Duffy, T.S. (2008) Mineralogy at the extremes, Nature, 451, 269-270.

EMSEV (2013). IUGG, http:/ / www.emsev-iugg.org/em sev/ (December 2013).

Everett, M.E., and Z. Martinec (2003). Spatiotemporal response of a conducting sphere under simulated geomagnetic storm conditions, Phys. Earth Planet. In., 138, 163-181.

FACEBOOK (2012). Permanent Long Period Magnetotelluric (MT) Network, https: / / www.facebook. $\mathrm{com} /$ pages / Permanent-Long-Period-Magnetotellu luric-MT-Network/158145917612101 (October 2012).

Fourie, C.J.S. (2011). The science and technology train: A support for geoscience training, research and service delivery in South Africa, S. Afr. J. Geol., 114, 585-592.

Freund, F. (2011). Pre-earthquake signals: Underlying physical processes: J. Asian Earth Sci., 41, 383-400.

Gauthier-Lafaye, F. (1997). The last natural nuclear fission reactor, Nature, 387, 337.

Georges, H.F. (1968). HF Doppler studies of traveling ionospheric disturbances, J. Atmos. Terr. Phys., 30, 735 -736, IN5 -IN8, 737-746.

Geospatial Information Authority of Japan (2010). Data download-MT (Magnetotellurics) data, http:/ / vldb. gsi.go.jp/sokuchi/geomag/menu_03/mt_data-e. html (October 2012).

Gil, P.M., L. Gurovich and B. Schaffer (2008). The electrical response of fruit trees to soil water availability 
and diurnal light-dark cycles, Plant Signal. Behav., 3, 1026-1029.

Gilbert, D., J.-L. Le Mouël, L. Lambs, F. Nicollin and F. Perrier (2006). Sap flow and daily electric potential variations in a tree trunk, Plant Sci., 171, 572-584.

Goupil, C., W. Seifert, K. Zabrocki, E. Müller and G.J. Snyder (2011). Thermodynamics of thermoelectric phenomena and applications, Entropy, 13, 14811517.

Gurovich, L.A. (2009). Real-time plant water potential assessment based on electrical signalling in higher plants, In: Proceedings World Congress on Computers in Agriculture, 7th, (Reno, Nevada, June 22-24), The American Society of Agricultural and Biological Engineers, 095875, https:/ / elibrary.asabe.org/ (June 2013).

Halekas, J., and K. Fox (2012). Why does the Earth's magnetotail cause lightning on the moon?, http:// www.quora.com/Heliophysics/Why-does-theEarths-magnetotail-cause-lightning-on-the-moon (June 2012).

Hata, M., I. Takumi and H. Yasukawa (2001). Electromagnetic-wave radiation due to diastrophism of magma dike growth in Izu-Miyake volcanic eruptions in Japan in 2000, Nat. Hazard. Earth Sys., 1, 43-51.

Hawkins, K.D., I.D.R. MacKinnon and H. Schneeberger (1995). Influence of chemistry on the pyroelectric effect in tourmaline, Am. Mineral., 80, 491-501.

Heki, K. (2011). Ionospheric electron enhancement preceding the 2011 Tohoku-Oki earthquake, Geophys. Res. Lett., 38, L17312; doi:10.1029/2011GL047908.

Helliwell, R.A., J.P. Katsufrakis and M.L. Trimpi (1973). Whistler-induced amplitude perturbation in VLF propagation, J. Geophys. Res., 78, 4679-4688.

Himes, C., E. Carlson, R.J. Ricchiuti, B.P. Otis and B.A. Parviz (2010). Ultralow voltage nanoelectronics powered directly, and solely, from a tree, IEEE Trans. Nanotechnol., 9, 2-5.

Hoblitt, R.P. (1994). An experiment to detect and locate lightning associated with eruptions of Redoubt Volcano, J. Volcanol. Geotherm. Res., 62, 499-517.

Honkura, Y., Y. Ogawa, M. Matsushima, S. Nagaoka, N. Ujihara and T. Yamawaki (2009). A model for observed circular polarized electric fields coincident with the passage of large seismic waves, J. Geophys. Res.: Solid Earth, 114, B10103; doi:10.1029/2008JB0 06117.

Hussein, A.M., W. Janischwskyj, M. Milewski, V. Shostak, F. Rachidi and J.S. Chang (2003). Comparison of current characteristics of lightning strokes measured at the CN Tower and at other elevated objects, In: Proceedings IEEE International Symposium on Electromagnetic Compatibility (August 18-22), 495-500.
Incorporated Research Institutions for Seismology (2012). USArray - Magnetotelluric Array, http:// www.usarray.org/researchers/obs/magnetotelluric (October 2012).

INTERMAGNET (2012). What is INTERMAGNET?, http:/ / www.intermagnet.org/ (March 2012).

ISTP SB RAS (2012). Observatories: Institute of SolarTerrestrial Physics, Russian Academy of Sciences, Siberian Branch, http: / / en.iszf.irk.ru/Observatories (October 2012).

James, M.R., S.J. Lane and J.S. Gilbert (2000). Volcanic plume electrification: Experimental investigation of a fracture-charging mechanism, J. Geophys. Res., 105, 16,641-16,649.

Jardani, A., J.P. Dupont and A. Revil (2006). Self-potential signals associated with preferential groundwater flow pathways in sinkholes, J. Geophys. Res., 111, B09204; doi:10.1029/2005JB004231.

Jardani, A., A. Revil, A. Bolève and J.P. Dupont (2008). Three-dimensional inversion of self-potential data used to constrain the pattern of groundwater flow in geothermal fields, J. Geophys. Res., 113, B09204; doi:10.1029/2007JB005302.

Jensen, K.A., and R.C. Ewing (2001). The Okélobondo natural fission reactor, southeast Gabon: Geology, mineralogy, and retardation of nuclear-reaction products, Geol. Soc. Am. Bull., 113, 32-62.

Jie Li,Yan-li Yi, Zhong-ke He, Xi-lei Cheng, Da-geng Zhang and Yun-bo Fang (2009). Effects of magnetic treatment on some soil microbial activities in brown earth, Chinese Journal of Soil Science; doi:CNKI: SUN:TRTB.0.2009-06-010.

Johnston, M.J.S. (1997). Review of electric and magnetic fields accompanying seismic and volcanic activity, Surv. Geophys., 18, 441 -476.

Jonassen, N. (2002). Electrostatics: Berlin, Springer, The Springer International Series in Engineering and Computer Science, 700, 188 pp.

Jordan, T., Y. Chen, P. Gasparini, R. Madariaga, I. Main, W. Marzocchi, G. Papadopoulos, G. Sobolev, K. Yamaoka and J. Zschau (2011). OPERATIONAL EARTHQUAKE FORECASTING. State of Knowledge and Guidelines for Utilization, Annals of Geophysics, 54 (4); doi:10.4401/ag-5350.

Jouniaux, L., and J.P. Pozzi (1995). Streaming potential and permeability of saturated sandstones under triaxial stress: Consequences for electrotelluric anomalies prior to earthquakes, J. Geophys. Res.: Solid Earth, 100, 10197-10209.

Jouniaux, L., and J.P. Pozzi (1997). Laboratory measurements anomalous $0.1-0.5 \mathrm{~Hz}$ streaming potential under geochemical changes: Implications for electrotelluric precursors to earthquakes, J. Geophys. 
Res.: Solid Earth, 102, 15335-15343.

Junfeng Shen, Xuhui Shen, Qian Liu and Na Ying (2010). The themo-electric effect of magnetite and the mechanism of geo-electric abnormalities during earthquakes, Geosci. Frontiers, 1, 99-104.

Kaladze, T.D., O.A. Pokhotelov, R.Z. Sagdeev, L. Stenflo and P.K. Shukla (2003). Planetary electromagnetic waves in the ionospheric E-layer, J. Atmos. Sol. Terr. Phys., 65, 757-764.

Kappenman, J.G., V.D. Albertson and N. Mohan (1981). Current transformer and relay performance in the presence of geomagnetically-induced currents, IEEE Transactions on Power Apparatus and Systems, PAS-100, 1078-1088.

Katzir, S. (2006). The Beginnings of Piezoelectricity: A Study in Mundane Physics, Dordrecht, The Netherlands, Springer, Boston Studies in Philosophy of Science, 246, $300 \mathrm{pp}$.

Kawase, T., S. Uyeda, M. Uyeshima and M. Kinoshita (1993). Possible correlation between geoelectric potential change in Izu-Oshima Island and the earthquake swarm off the east Izu Peninsula, Japan, Tectonophysics, 224, 83-93.

Keller, G.V. (1968). Statistical study of electric fields from Earth-return tests in the western states compared with natural electric fields, IEEE Transactions on Power Apparatus and Systems, PAS-87, 1050-1057.

Kerridge, D. (2001). INTERMAGNET: Worldwide near-real-time geomagnetic observatory data, In: Proceedings of European Space Agency's Space Weather Workshops, ESTEC 3rd (Noordwijk, The Netherlands, December 17-19); http: / / esa-space weather.net/spweather/workshops/SPW_W3 / PROCEEDINGS_W3/index.html (March 2012).

Larsen, J.C. (1992). Transport and heat flux of the Florida Current at 27 degrees $\mathrm{N}$ derived from crossstream voltages and profiling data: theory and observations, Phil. Trans. Phys. Sci. Eng., 338, 169-236.

Leinov, E., J. Vinogradov and M.D. Jackson (2010). Salinity dependence of the thermoelectric coupling coefficient in brine-saturated sandstones, Geophys. Res. Lett., 37, L23308; doi:10.1029/2010GL045379.

Lile, O.B. (1996). Self potential anomaly over a sulphide conductor tested for use as a current source, J. Appl. Geophys., 36, 97-104.

Love, C.J., Shuguang Zhang and A. Mershin (2008). Source of sustained voltage difference between the xylem of a potted Ficus benjamina tree and its soil, PLOS One, 3, e2963; doi:10.1371/journal.pone.000 2963.

Madey, T.E., R.E. Johnson and T.M. Orlando (2002). Far-out surface science: Radiation-induced surface processes in the solar system, Surf. Sci., 500, 838-858.
Malin, S.R.C. and B.M. Hodder (1982). Was the 1970 geomagnetic jerk of internal or external origin?, Nature, 296, 726-728.

Mason, W.P. (1950). Piezoelectric Crystals and Their Application to Ultrasonics, New York, D. Van Nostrand Company, Inc., 508 pp.

Mather, K.B., E.J. Gauss and G.R. Cresswell (1964). Diurnal variations in the power spectrum and polarization of telluric currents at conjugate points, $\mathrm{L}=2.6$, Aust. J. Phys., 17, 340-388.

Matsumoto, H., M. Ikeya and C. Yamanaka (1998). Analysis of barber-pole color and speckle noises recorded 6 and a half hours before the Kobe earthquake, Jpn. J. Appl. Phys., 37, L1409-L1411.

McNutt, S.R., and E.R. Williams (2010). Volcanic lightning: Global observations and constraints on source mechanisms, Bull. Volcanol., 72, 1153-1167.

Molina-Cuberos, G.J., W. Stumptner, H. Lammer, N.I. Kömle and K. O’Brien (2001). Cosmic ray and UV radiation models on the ancient Martian surface, Icarus, 154, 216-222.

MTNET (2012). MTNet, http://mtnet.dias.ie/main/ (October 2012).

Munro, G.H. (1958). Travelling ionospheric disturbances in the F region, Aust. J. Phys., 11, 91-112.

Nagao, H., T. Iyemori, T. Higuchi and T. Araki (2003). Lower mantle conductivity anomalies estimated from geomagnetic jerks, J. Geophys. Res., 108, 2254; doi:10.1029/2002JB001786.

Nichitiu, F., J.R. Drummond, J. Kar and J. Zou (2009). An extreme $\mathrm{CO}$ pollution event over Indonesia measured by the MOPITT instrument, Atmos. Chem. Phys. Discuss., 9, 1211-1233.

Ohta, K., S. Onoda, K. Hirose, R. Sinmyo, K. Shimizu, N. Sata, Y. Ohishi and A. Yasuhara (2008). The electrical conductivity of post-perovskite in Earth's D" layer, Science, 320, 89-91.

Osella, A., A. Favetto and E. López (1998). Currents induced by geomagnetic storms on buried pipelines as a cause of corrosion, J. Appl. Geophys., 38, 219-233.

Oster, L., V. Yaskolko and J. Haddad (1999). Classification of exoelectron emission mechanisms, Phys. Status Solidi, 174, 431-439.

Perrone, L., L.P. Korsonova and A. Mikhailov (2010). Ionospheric precursors for crustal earthquakes in Italy, Annales Geophysicae, 28, 941-950.

Pham, V.N., D. Boyer, G. Chouliaras, J.L. Le Mouël, J.C. Rossignol and G.N. Stavrakakis (1998). Characteristics of electromagnetic noise in the Ioannina region (Greece): A possible origin for so called "Seismic Electric Signal” (SES), Geophys. Res. Lett., 25, 2229-2232.

Popov, K.V., V.A. Liperovsky, C.V. Meister, P.F. Biagi, E.V. Liperovskaya and A.S. Silina (2004). On ionos- 
pheric presursors of earthquakes in scales of 2-3 h, Phys. Chem. Earth, 29, 529-535.

Price, P.R. (2002). Geomagnetically induced current effects on transformers, IEEE Trans. Power Del., 17, 1002-1008.

Probstein, R.F., and R.E. Hicks (1993). Removal of contaminants from soils by electric fields, Science, 260, 498-503.

Pulinets, S.A., and K.A. Boyarchuk (2004). Ionospheric Precursors of Earthquakes, Berlin, Springer, 289 pp.

Pulinets, S.A. (2007). Natural radioactivity, earthquakes, and the ionosphere, Eos, Trans. Amer. Geophys. Union, 88, 217-219.

Pulkkinen, A., R. Pirjola and A. Viljanen (2007). Determination of ground conductivity and system parameters for optimal modeling of geomagnetically induced current flow in technologyical systems, Earth Planets Space, 59, 999-1006.

Pulkkinen, A., R. Pirjola and A. Viljanen (2008). Statistics of extreme geomagnetically induced current events, Space Weather, 6, S07001, doi:10.1029/2008 SW000388.

Ralshovsky, T.M., and L.N. Komarov (1993). SES activity and the Earth's electric potential, Tectonophysics, 224, 95-101.

Raymond, M.V., and D.M. Smyth (1996). Defects and charge transport in perovskite ferroelectrics, J. Phys. Chem. Solids, 57, 1507-1511.

Revil, A., V. Naudet, J. Nouzaret, and M. Pessel (2003). Principles of electrography applied to self-potential electrokinetic sources and hydrogeological applications, Water Resour. Res., 39, 1114; doi:10.1029/20 $01 \mathrm{WR} 000916$.

Salvati, M.A., U.S. Inan, T.J. Rosenberg and A.T. Weatherwax, (2000). Solar wind control of polar chorus, Geophys. Res. Lett., 27, 649-652.

Sands, D.E. (1994). Introduction to Crystallography: New York, Dover Publications, 192 pp.

Schieber, D. (1986). Electromagnetic Induction Phenomena, Berlin, Springer, Springer Series in Electronics and Photonics, 16, $312 \mathrm{pp}$.

Schlatter, N. (2008). Whistlers: Discovering the plasmapause, http:/ / www.staff.alfvenlab.kth.se/nickolay. ivchenko/teach/pro08/proj1.pdf (July 2012).

Schlegel, K., and M. Füllekrug (1999). Schumann resonance parameter changes during high-energy particle precipitation: J. Geophys. Res., 104, 10111-10118.

Shankland, T.J. (1975). Electrical conduction in rocks and minerals: Parameters for interpretation, Phys. Earth Planet. In., 10, 209-219.

Shibkov, A.A., M.A. Zheltov, V.V. Skvortsov, R.Y. Kol'tsov and A.V. Shuklinov (2005). Electromagnetic emission under uniaxial compression of ice: I. Iden- tification of nonstationary processes of structural relaxation by electromagnetic signals, Crystallogr. Rep., 50, 994-1004.

Shiokawa, K., Y. Otsuka, C. Ihara, T. Ogawa and F.J. Rich (2003). Ground and satellite observations of nighttime medium-scale traveling ionospheric disturbance at midlatitude: J. Geophys. Res.: Space, 108, 2156-2202.

Simpson, F. and K. Bahr (2005). Practical Magnetotellurics: Cambridge, Cambridge University Press, $272 \mathrm{pp}$.

Singh, C., and O.P. Singh (2007). Simultaneous ionospheric E- and F-layer perturbations caused by some major earthquakes in India, Annales Geophysicae, 50, 111-122.

SPRINGER (2012). SpringerMaterials The LandoltBörnstein Database, http:/ / www.springermaterials. $\mathrm{com} / \mathrm{docs} /$ index.html (May 2012).

Stille, P., F. Guathier-Lafaye, K.A. Jensen, S. Salah, G. Bracke, R.C. Ewing, D. Louvat and D. Million (2003). REE mobility in groundwater proximate to the natural fission reactor at Bangombé (Gabon), Chem. Geol., 198, 289-304.

Stoll, J., J. Bigalke and E.W. Grabner (1995). Electrochemical modelling of self-potential anomalies, Surv. Geophys., 16, 107-120.

Stubbs, T.J., J.S. Halekas, W.M. Farrell and R.R. Vondrak (2007). Lunar surface charging: A global perspective using lunar prospector data, In: H. Krueger and A. Graps (eds.), Workshop on Dust in Planetary Systems (September 26-30, 2005, Kauai, Hawaii), ESA SP-643, 181-184.

Szuszczewics, E.P., P. Blanchard, P. Wilkinson, G. Crowley, T. Fuller-Rowell, P. Richards, M. Abdu, T. Bullett, R. Hanbaba, J.P. Lebreton, M. Lester, M. Lockwood, G. Millward, M. Wild, S. Pulinets, B.M. Reddy, I. Stanislawska, G. Vannaroni and B. Zolesi (1998). The first real-time worldwide ionospheric predictions network: An advance in support of spaceborne experimentation, on-line model validation, and space weather, Geophys. Res. Lett., 25, 449-452.

Takeuchi, A., and T. Nagao (2013). Activation of hole charge carriers and generation of electromotive force in gabbro blocks subjected to nonuniform loading, J. Geophys. Res.: Solid Earth, 118, 915-925.

Toramaru, A., and S. Yamauchi (2012). Effect of permeable flow on cyclic layering in solidifying magma bodies: Insights from an analog experiment of diffusion-precipitation, In: European Geosciences Union General Assembly Conference Abstracts, 14, 3464.

Troshichev, O.A., A. Frank-Kamenetsky, G. Burns, M. Fuellekrug, A. Rodger and V. Morozov (2004). The relationship between variations of the atmospheric 
electric field in the southern polar region and thunderstorm activity, Adv. Space Res., 34, 1801-1805.

Uman, M.A., and E.P. Krider (1982). A review of natural lightning: Experimental data and modeling, IEEE Trans. Electromagn. Compat., EMC-24, 79-112.

Uman, M.A. (1994). Natural lightning, IEEE Trans. Ind. Appl., 30, 785e90; doi:10.1109/ICPS.1993.290594.

Uyeda, S., M. Kamogawa and H. Tanaka (2009). Analysis of electrical activity and seismicity in the natural time domain for the volcanic-seismic swarm activity in 2000 in the Izu Island region, Japan, J. Geophys. Res.: Solid Earth, 114, B02310; doi:10.1029/2007JB 005332.

Uyeshima, M., H. Utada and Y. Nishida, (2001). Network-magnetotelluric method and its first results in central and eastern Hokkaido, NE Japan, Geophys. J. Int., 146, 1-19.

Varotsos, P., K. Alexopoulos and M. Lazaridou (1993). Latest aspects of earthquake prediction in Greece based on seismic electric signals, II, Tectonophysics, 224, 1-37.

Varotsos, P.A., N.V. Sarlis and E.S. Skordas (2011). Natural Time Analysis: The New View of Time, Berlin, Springer-Verlag, $449 \mathrm{pp}$.

Verrier, V., and P. Rochette (2002). Estimating peak currents at ground lightning impacts using remanent magnetization, Geophys. Res. Lett., 29, 14.1-14.4.

Viljanen, A., O. Amm and R. Pirjola (1999). Modeling geomagnetically induced currents during different ionospheric situations, J. Geophys. Res., 104, 2805928071.

Viljanen, A., A. Pulkkinen, R. Pirjola, K. Pajunpää, P. Posio and A. Koistinen (2006). Recordings of geomagnetically induced currents and a nowcasting service of the Finnish natural gas pipeline system, Space Weather, 4, S10004; doi:10.1029/2006SW000234.

Voigt, W. (1910). Lehrbuch der kristallphysik, mit ausschluss der kristalloptik (Textbook on crystal physics, excluding crystal optics), Berlin, Druck und Verlag von B.G. Teubner, 964 pp.

von Baeckmann, W., W. Schwenk and W. Prinz (1997). Handbook of Cathodic Corrosion Protection, Houston, Texas, Gulf Professional Publishing, 568 pp.

Walker, C.V. (1861). On magnetic storms and Earthcurrents, Phil. Trans. R. Soc. London, 151, 89-131.

Wescott, E.M., and D.D. Sentman (2002). Geophysical electromagnetic sounding using HAARP, Department of the Navy, Office of Naval Research (ONR) Grant No. N00014-97-1-0995, 13 pp.

Wong, J.S.H., R.E. Hicks and R.F. Probstein (1997). EDTA-enhanced electroremediation of metal-contaminated soils, J. Hazard. Mater., 55, 61-79.

Xuhui Shen, Xuemin Zhang, Lanwei Wang, Huaran
Chen, Yun Wu, Shigeng Yuan, Junfeng Shen, Shufan Zhao, Jiadong Qian and Jianhai Ding (2011). The earthquake-related disturbances in ionosphere and project of the first China seismo-electromagnetic satellite, Earthquake Science, 24, 639-650.

Yamaguchi, T., and S. Hashimoto (2012). A green battery by pot-plant power, IEEJ Trans. Electr. Electr., 7, 441-442.

Yoshino, T., G. Manthilake, T. Matsuzaki and T. Kastura (2008). Dry mantle transition zone inferred from the conductivity of wadsleyite and ringwoodite, Nature, 451, 326-329.

Yoshino, T. (2010). Laboratory electrical conductivity measurement of mantle minerals, Surv. Geophys., 31, 163-206.

Zhang Yun-qiang, Li Sheng-rong, Chen Hai-yan, Xue Jian-ling, Sun Wen-yan and Zhang Xu (2010). Research on the typomorphisms of compositions and thermoelectric characteristics of pyrite from Zhaodaoshan gold deposit in the eastern Shanding province, Journal of Mineralogy and Petrology, 03, http://en.cnki.com.cn/Article_en/CJFDTOTALKWYS201003003.htm (May 2012).

Zhdanov, M.S., R.B. Smith, A. Gribenko, M. Cuma and M. Green (2011). Three-dimensional inversion of large-scale EarthScope magnetotelluric data based on the integral equation method: Geoelectrical imaging of the Yellostone conductive mantle plume, Geophys. Res. Lett., 38, L08307; doi:10.1029/2011 GL046953.

Zlotnicki, J., and Y. Nishida (2003). Review on morphological insights of self-potential anomalies on volcanoes, Surv. Geophys., 24, 291-338.

Zolotov, O.V., A.A. Mangaladze, I.E. Zakharenkova, O.V. Martynenko and I.I. Shagimuratov (2012). Physical interpretation and mathematical simulation of ionospheric precursors of earthquakes at midlatitudes, Geomagnetism and Aeronomy, 52, 390-397.

\footnotetext{
${ }^{\star}$ Corresponding author: Daniel S. Helman, California State University Long Beach, Department of Geological Sciences, Long Beach, CA, United States; email: danielhelmanteaching@yahoo.com.

C 2013 by the Istituto Nazionale di Geofisica e Vulcanologia. All rights reserved.
} 